\title{
Apakah Hipertensi Arteri Pulmonal Merupakan Faktor Risiko Malnutrisi pada Penyakit Jantung Bawaan Asianotik dengan Pirau Kiri ke Kanan
}

\author{
Arif Handiarsa, Sasmito Nugroho, Endy Paryanto Prawirohartono \\ Bagian Ilmu Kesehatan Anak Fakultas Kedokteran Universitas Gadjah Mada/RSUP Dr. Sardjito, Yogyakarta
} Latar belakang. Penyakit jantung bawaan (PJB) asianotik pirau kiri ke kanan menyebabkan terjadinya hipertensi arteri pulmonal
(HAP). Malnutrisi merupakan komplikasi penting berhubungan dengan PJB, kejadiannya semakin meningkat bila disertai HAP,
PJB sianotik, dan gagal jantung kongestif.
Tujuan.Mengetahui HAP sebagai faktor risiko malnutrisi pada anak dengan PJB asianotik pirau kiri ke kanan.
Metode. Penelitian dengan design kasus-kontrol. Subjek penelitian adalah anak berusia 6 bulan -18 tahun dengan PJB asianotik pirau
kiri ke kanan yang berobat ke Poliklinik Kardiologi Anak RSUP Dr. Sardjito Yogyakarta periode Juni-Juli 2013 yang memenuhi kriteria
inklusi. Sampel diambil secara konsekutif sampling, setelah didapatkan kelompok kasus (anak yang mengalami malnutrisi) dan kontrol
(anak yang tidak mengalami malnutrisi), kemudian diidentifikasi adanya faktor risiko HAP berdasarkan data rekam medis. Analisis
univariat untuk menghitung odds ratio (OR) dan interval kepercayaan 95\% (IK95\%) serta analisis multivariat dengan regresi logistik.
Hasil. Terdapat 76 pasien diikutsertakan, sampel kelompok kasus 38 ( $50 \%$ ), kelompok kontrol 38 (50\%) anak. Analisis multivariat
menunjukkan HAP tidak memiliki hubungan kuat sebagai faktor risiko terjadinya malnutrisi pada anak dengan PJB asianotik pirau
kiri ke kanan dengan nilai p=0,006, OR 0,100 (IK95\%: 0,020-0,512). Lama terapi $>36$ bulan pada PJB asianotik pirau kiri ke kanan
meningkatkan risiko kejadian malnutrisi secara bermakna dibandingkan lama terapi <12 bulan dengan nilai p=0,035, OR 4,095
(IK95\%: 1,107-15,155).

Kesimpulan. Hipertensi arteri pulmonal bukan merupakan faktor risiko terjadinya malnutrisi pada PJB asianotik pirau kiri ke kanan tetapi merupakan faktor protektif. Sari Pediatri 2016;18(1):12-6

Kata kunci: HAP, faktor risiko, malnutrisi, PJB asianotik

\section{Is Pulmonary Arterial Hypertension a Risk Factor Malnutrition for Acyanotic Heart Disease Patient with Left to Right Shunt}

Arif Handiarsa, Sasmito Nugroho, Endy Paryanto Prawirohartono

Background. Acyanotic congenital heart disease (CHD) with left-to-right shunt may lead to pulmonary arterial hypertension (PAH). Malnutrition is an important complication associated with CHD, when accompanied by PAH, cyanotic heart disease and congestive heart failure.

Objective. To confirm if PAH is a risk factor for malnutrition in children with a cyanotic CHD with left-to-right shunt.

Methods. A case control study was performed. Samples were children, with age 6 months - 18 years with a cyanotic CHD with left-to-right shunt who came to the Pediatric Cardiology Clinic of Dr. Sardjito hospital during the period of June-July 2013 and met the inclusion criteria. Samples were taken consecutively matched with a control for each acquired case, subsequently the presence of risk factors for PAH were identified based data in the medical records. Univariate analysis to calculate odds ratios (OR) and 95\% confidence intervals $(95 \% \mathrm{CI})$ and multivariate analysis with logistic regression tests were conducted.

Results. A total of 76 patients were included in the study. The number of subjects in the case group were 38 children (50\%), matched with other 38 children as controls $(50 \%)$. Multivariate analysis showed that PAH does not have a strong relationship as a risk factor for malnutrition in children with a cyanotic congenital heart disease with left to right shunt with a value of $\mathrm{p}=0.006, \mathrm{OR} 0.100(95 \% \mathrm{CI}$ 0.020 to 0.512 ). Duration of therapy $>36$ months for a cyanotic CHD pediatric patients with left to right shunt significantly increases the risk of malnutrition incidence compared to therapy $<12$ months, with a value of $\mathrm{p}=0.035$, OR 4.095 (95\% CI 1.107 to 15.155$)$. Conclusion. PAH is not a risk factor for malnutrition in a cyanotic CHD with left to right shunt but it is a protective factor.

Sari Pediatri 2016;18(1):12-6

Keywords: PAH, risk factors, malnutrition, a cyanotic CHD

Alamat korespondensi: Dr. Sasmito Nugroho, Sp.A(K). Bagian IKA FK UGM/RSUP Dr. Sardjito, Yogyakarta. Tel. +62 (274) 587333, Jl. Kesehatan No. 1, E-mail: sasmito@yogya.wasantara.net.id 
$\mathrm{P}$ enyakit jantung bawaan adalah suatu kelainan bawaan yang cukup banyak ditemukan dengan insiden antara 8 - 10 kejadian setiap 1000 kelahiran hidup. Angka kejadian PJB di Indonesia cukup tinggi, yaitu 45000 bayi Indonesia terlahir dengan PJB tiap tahun. Penyakit jantung bawaan asianotik merupakan kelompok penyakit terbanyak, yakni 75\% dari semua PJB, sedangkan sisanya merupakan kelompok PJB sianotik (25\%). Defek septum ventrikel (DSV) merupakan salah satu jenis $\mathrm{PJB}$ asianotik yang paling sering ditemukan, yaitu 20\%-30\% dari seluruh kasus PJB. ${ }^{1-4}$

Penelitian yang dilakukan oleh Leite $\mathrm{dkk}^{5}$ menyebutkan bahwa faktor HAP pada PJB asianotik berhubungan dengan tingginya angka kejadian malnutrisi $(\mathrm{p}=0,0140)$. Penelitian serupa dilakukan oleh Varan $\mathrm{dkk}^{6}$ mendapatkan bahwa kejadian malnutrisi ringan 46\%, malnutrisi sedang 31\%, malnutrisi berat $8 \%$ pada kelompok PJB asianotik dengan HAP, sedangkan kejadian malnutrisi ringan $60 \%$ pada PJB asianotik tanpa HAP. Penelitian tersebut menunjukkan faktor HAP meningkatkan kejadian malnutrisi.

Berdasarkan penelitian sebelumnya diketahui banyak faktor yang memengaruhi kejadian malnutrisi, dan HAP dapat meningkatkan risiko malnutrisi pada anak dengan PJB. Peneliti ingin meneliti lebih lanjut mengenai HAP sebagai faktor risiko malnutrisi pada PJB asianotik pirau kiri ke kanan dengan metode penelitian yang berbeda dengan penelitian sebelumnya.

\section{Metode}

Penelitian kasus kontrol pada anak dengan PJB asianotik pirau kiri ke kanan dilakukan di Poliklinik Kardiologi Anak RSUP Dr. Sardjito. Kelompok dibagi menjadi kelompok kasus (PJB asianotik pirau kiri ke kanan yang mengalami malnutrisi) dan kontrol (PJB asianotik pirau kiri ke kanan yang tidak mengalami malnutrisi). Data penelitian didapatkan dengan cara anamnesis, pemeriksaan fisik, pengukuran antropometri, dan berdasarkan data rekam medis mulai Juni 2013 hingga Juli 2013. Kriteria inklusi adalah anak yang berusia 6 bulan - 18 tahun (khusus untuk anak dengan riwayat lahir prematur menggunakan usia koreksi yaitu usia sebenarnya jika anak lahir aterm), anak dengan PJB asianotik pirau kiri ke kanan, berobat ke Poliklinik Kardiologi Anak RSUP Dr. Sardjito Yogyakarta dan orang tua telah menandatangani proxy consent.

Besar sampel penelitian dihitung dengan rumus besar sampel minimal untuk studi kasus kontrol tidak berpasangan. Standar deviasi pada tingkat kesalahan 5\%, tingkat kepercayaan 95\% $(1,96)$ dan power penelitian $80 \%$. Besar sampel yang diperlukan berdasarkan asumsi pada kelompok kasus dan kontrol masing-masing 38 anak. Sampel dipilih secara consecutive sampling berdasarkan kriteria inklusi dan eksklusi. Penelusuran faktor risiko terdapatnya HAP dilakukan melalui rekam medis dan dilakukan analisis secara statistik.

Analisis data dilakukan dengan menggunakan program statistik SPSS versi 17 . Analisis univariat digunakan untuk menghitung odds ratio (OR) dan interval kepercayaan 95\% (IK 95\%) malnutrisi pada PJB asianotik pirau kiri ke kanan. Usia saat awal didiagnosis PJB asianotik, lama terapi dan tipe PJB asianotik pirau kiri ke kanan sebagai variabel perancu juga dianalisis secara univariat. Variabel yang memiliki nilai $\mathrm{p}<0,2$ pada analisis univariat dianalisis multivariat dengan regresi logistik.

\section{Hasil}

Didapatkan 76 subyek penelitian yang terdiri atas 38 kelompok kasus dan 38 kontrol. Karakteristik dasar yang dinilai tertera pada Tabel 1. Anak dengan PJB asianotik pirau kiri ke kanan yang mengalami hipertensi pulmonal lebih banyak dikelompok kasus dibanding kelompok kontrol. Anak dengan PJB asianotik pirau kiri ke kanan yang mengalami malnutrisi 38 (50\%), sedangkan yang tidak mengalami malnutrisi 38 (50\%) anak. Perbedaan faktor HAP antara kelompok kasus dengan kontrol bermakna dalam meningkatkan risiko malnutrisi $\mathrm{p}=0,002(\mathrm{p}<0,005)$; dengan adjusted OR 8,880 (IK95\%: 1,828-43,138). Hasil analisis variabel tersebut tertera pada Tabel 2.

Variabel yang berpengaruh terhadap angka kejadian malnutrisi setelah dianalisis dengan multivariat adalah lama terapi sebagai variabel perancu (confounder), yaitu lama terapi $>36$ bulan dibanding dengan $<12$ bulan dengan nilai $\mathrm{p}=0,035$, dengan adjusted OR 4,095 (IK95\%:1,107-15,155). Dengan demikian, dapat disimpulkan bahwa lama terapi PJB asianotik pirau kiri ke kanan >36 bulan meningkatkan risiko kejadian malnutrisi secara bermakna (4x lipat) dibanding dengan lama terapi $<12$ bulan. 
Tabel 1. Karakteristik dasar subyek penelitian

\begin{tabular}{lcc}
\hline Karakteristik & $\begin{array}{c}\text { Kasus } \\
\mathrm{n}(\%)\end{array}$ & $\begin{array}{c}\text { Kontrol } \\
\mathrm{n}(\%)\end{array}$ \\
\hline Usia (bulan, \%) & & \\
$\quad<24$ & $10(26)$ & $10(26)$ \\
$24-36$ & $7(18)$ & $6(16)$ \\
$\quad>36$ & $21(56)$ & $22(58)$ \\
Jenis kelamin (\%) & & \\
$\quad$ Laki-laki & $15(39)$ & $17(45)$ \\
$\quad$ Perempuan & $23(61)$ & $21(55)$ \\
Berat lahir (gram) & $3(8)$ & $6(16)$ \\
$\quad<2500$ & $35(92)$ & $32(84)$ \\
$\geq 2500$ & $13(34)$ & $7(18)$ \\
Status ekonomi* & $25(66)$ & $31(82)$ \\
$\quad$ Miskin & & \\
$\quad$ Tidak miskin & $16(42)$ & $9(24)$ \\
Tipe PJB asianotik pirau kiri ke kanan & $3(8)$ & $6(16)$ \\
$\quad$ DSV & $19(50)$ & $23(60)$ \\
$\quad$ DAP & & \\
$\quad$ DSA & $13(34)$ & $1(3)$ \\
Hipertensi arteri pulmonal & $25(66)$ & $37(97)$ \\
$\quad$ Ya & & \\
$\quad$ Tidak & &
\end{tabular}

*Penilaian batas garis kemiskinan berdasarkan indikator Badan Pusat Statistik (BPS).

DSV: Defek septum ventrikel ; DAP: Duktus arteriosus persisten; DSA: Defek septum atrium

Tabel 2. Analisis univariat dan multivariat faktor risiko malnutrisi pada anak dengan PJB asianotik pirau kiri ke kanan

\begin{tabular}{|c|c|c|c|c|c|c|}
\hline \multirow[t]{2}{*}{ Variabel } & \multicolumn{3}{|c|}{ Univariat } & \multicolumn{3}{|c|}{ Multivariat } \\
\hline & $\mathrm{N}(\%)$ & OR & IK95\% & Nilai $p$ & OR & IK95\% \\
\hline Hipertensi arteri pulmonal & $14(18,4)$ & 8,880 & $1,828-43,138$ & 0,002 & 0,100 & $0,020-0,512$ \\
\hline \multicolumn{7}{|c|}{$\begin{array}{l}\text { Usia awal saat didiagnosis PJB } \\
\text { asianotik pirau kiri ke kanan } \\
\text { (bulan) }\end{array}$} \\
\hline$>36$ & $43(57)$ & 1,768 & $0,484-6,462$ & 0,389 & & \\
\hline $12-36$ & $21(28)$ & 1,273 & $0,304-5,329$ & 0,741 & & \\
\hline$<12$ & $12(15)$ & & Pembanding & & & \\
\hline \multicolumn{7}{|l|}{ Lama terapi (bulan) } \\
\hline$>36$ & $19(25)$ & 3,611 & $1,084-12,029$ & 0,036 & 4,096 & $1,107-15,155$ \\
\hline $12-36$ & $25(33)$ & 2,121 & $0,731-6,158$ & 0,167 & & \\
\hline$<12$ & $32(42)$ & & Pembanding & & & \\
\hline \multicolumn{7}{|c|}{$\begin{array}{l}\text { Tipe PJB asianotik dengan pirau } \\
\text { kiri ke kanan }\end{array}$} \\
\hline DSV & $41(54,0)$ & 0,440 & $0,158-1,225$ & 0,116 & & \\
\hline DAP & $10(13,2)$ & 1,826 & $0,413-8,074$ & 0,427 & & \\
\hline DSA & $25(32,8)$ & & Pembanding & & & \\
\hline
\end{tabular}


Variabel lain setelah dianalisis dengan multivariat adalah HAP dengan nilai $\mathrm{p}=0,006$, dengan adjusted OR 0,100 (IK95\%: 0,020-0,512) sehingga dapat disimpulkan bahwa faktor HAP merupakan faktor protektor terjadinya malnutrisi dan merupakan faktor protektif malnutrisi karena $\mathrm{OR}<1$. Usia awal didiagnosis PJB asianotik pirau kiri ke kanan dengan adjusted OR 0,52 (IK95\%: 0,25-1,07), lama terapi 12-36 bulan dibanding dengan lama terapi $<12$ bulan dengan adjusted OR 0,75 (IK95\%: 0,28-1,97), dan tipe PJB asianotik pirau kiri ke kanan dengan adjusted OR 0,76 (IK95\%: 0,23-2,54) tidak ditampilkan pada hasil analisis multivariat karena hasilnya tidak bermakna.

\section{Pembahasan}

Hipertensi arteri pulmonal merupakan komplikasi PJB asianotik pirau kiri ke kanan. Pernyataan ini tidak didukung oleh penelitian kami karena hasil analisis multivariat mendapatkan bahwa HAP bukan merupakan faktor risiko yang memengaruhi kejadian malnutrisi, tetapi faktor HAP merupakan faktor protektif terhadap kejadian malnutrisi pada anak dengan PJB asianotik pirau kiri ke kanan. Hasil analisis tersebut serupa dengan penelitian yang dilakukan oleh Altin dkk ${ }^{7}$ yang melaporkan bahwa tidak ada perbedaan antara kelompok PJB asianotik pirau kiri ke kanan dengan HAP dan kelompok PJB asianotik pirau kiri ke kanan tanpa HAP dengan kejadian malnutrisi.

Hasil penelitian kami berbeda dengan penelitian lain yang dilakukan oleh Rahayuningsih ${ }^{8}$ yang melaporkan HAP merupakan faktor penyebab malnutrisi pada PJB asianotik. Penelitian serupa juga dilakukan oleh Leite $\mathrm{dkk}^{5}$ yang melaporkan bahwa faktor HAP behubungan dengan malnutrisi. Mayoritas tipe PJB asianotik pirau kiri ke kanan pada penelitian kami adalah tipe DSA, kejadian HAP terbanyak terdapat pada usia dewasa. Sementara subyek penelitian kami usia $\leq 18$ tahun sehingga kejadian HAP hanya sedikit yang mungkin dapat menyebabkan hasil penelitian tidak sesuai dengan hipotesis.

Lama terapi yang seharusnya menjadi faktor confounding menjadi variabel lain yang dianggap memengaruhi terjadinya malnutrisi. Faktor lama terapi meningkatkan peluang terjadinya malnutrisi 4 kali lipat pada anak dengan lama terapi $>36$ bulan dibanding dengan anak dengan lama terapi $<12$ bulan. Lama terapi yang diberikan berkaitan dengan lamanya pasien mengalami PJB asianotik tersebut. Selain dampak PJB asianotik itu sendiri, juga terdapat efek samping pengobatan yang tidak diinginkan, yaitu anorexia yang dapat mengganggu asupan nutrisi. Hal tersebut didukung oleh hasil penelitian yang dilakukan oleh Okoromah dkk, ${ }^{9}$ yang melaporkan lama durasi gejala PJB yang merupakan faktor risiko malnutrisi. Keever $\mathrm{dkk}^{10}$ melaporkan faktor risiko terjadinya malnutrisi pada PJB adalah berkurangnya suplementasi gizi. Hassan $\mathrm{dkk}^{11}$ melaporkan bahwa salah satu prediktor malnutrisi pada PJB adalah riwayat asupan nutrisi yang buruk dengan.

Kelemahan penelitian case-control adalah data mengenai pajanan faktor risiko diperoleh dengan mengandalkan daya ingat atau catatan medis. Daya ingat responden ini menyebabkan terjadinya recall bias. Data sekunder, dalam hal ini catatan medis rutin yang sering dipakai sebagai sumber data, juga tidak begitu akurat. Kelemahan lain adalah incidence rate yang tidak dapat diberikan. Penelitian juga tidak dapat dipakai untuk menentukan lebih dari 1 variabel dependen. ${ }^{12}$

Diperlukan penelitian lanjutan dengan menggunakan metode penelitian yang lebih baik, yaitu dengan kohort prospektif sehingga dapat dinilai peran HAP memodifikasi kejadian malnutrisi pada PJB asianotik dengan pirau kiri ke kanan.

\section{Kesimpulan}

Hipertensi arteri pulmonal bukan merupakan faktor risiko malnutrisi pada PJB asianotik pirau kiri ke kanan tetapi merupakan faktor protektif. Kejadian malnutrisi pada PJB asianotik pada penelitian ini dipengaruhi oleh lama terapi, yaitu lama terapi $>36$ bulan meningkatkan risiko kejadian malnutrisi secara bermakna.

\section{Daftar pustaka}

1. Madiyono B, Rahayuningsih SE. Penanganan penyakit jantung anak di Indonesia. Seminar dan workshop kardiologi sehari. Menuju cardiac centre yang handal. Penanganan penyakit jantung anak di Indonesia. RSUP Dr. Sardjito - OLVG - FK UGM; 2000.

2. Nugroho S. Prevensi dan deteksi dini penyakit kardiovaskular pada Anak. Continuing medical education. One day symposium. an update management 
of cardiac emergency for adult and pediatric on primary health care. Yogyakarta: Universitas Muhammadiyah Yogyakarta; 2009.

3. Nurani N. Manajemen nutrisi pada bayi dan anak dengan penyakit jantung bawaan (PJB). Continuing professional development. Winaya Waidya Anarawata. Penanganan kasus-kasus invasif dan non-invasif pada bayi dan anak dalam praktek sehari-hari. Yogyakarta: Bagian Ilmu Kesehatan Anak Fakultas Kedokteran UGM/RSUP Dr. Sardjito; 2011.

4. Wahab AS. Defek septum ventrikel, kardiologi anak. Penyakit jantung kongenital yang tidak sianotik. Jakarta: EGC; 2009.

5. Leite HP, de Camargo CAC, Fisberg M. Nutritional status of children with congenital heart disease and left-to-right shunt. The importance of the presence of pulmonary hypertension. Arq Bras Cardiol 1995; 65:403-7.

6. Varan B, Tokel K, Yilmaz G. Malnutrition and growth failure in cyanotic and acyanotic congenital heart disease with and without pulmonary hypertension. Arch Dis Child 1999;81:49-52.
7. Altin H, Karatas Z, Sap F, Alp H, Baysal T, Karaaslan S, Oran B. The association between pulmonary arterial hypertension and malnutrition in children with congenital heart diseases with left-to-right shunt: an observational study. Anadolu Kardiyol Derg 2012;12:150-9.

8. Rahayuningsih SE. Hubungan antara defek septum ventrikel dan status gizi. Sari Pediatri 2011;13:137-41.

9. Okoromah CAN, Ekure EN, Lesi FEA, Okunowo WO, Tinjani BO, Okeiyi JC. Prevalence, Profile and predictors of malnutrition in children with congenital heart defects : a case-control observational study. Arch Dis Child (2011). doi:10.1136/2 of 7 adc.2009.176644.

10. Keever, V., Cruz, A. P., Castillo, $\mathrm{H}$ and Espinosa A.. Frequency and risk factors associated with malnutrition in children with congenital cardiopathy. Salud Publica Mex 2001; 43:313-23.

11. Hassan BA, Albanna EA, Morsy SM, Siam AG, Al Shafie MM, Elsaadany HF, dkk. Nutritional status in children with un-operated congenital heart disease: an Egyptian center experience. Front Pediatr 2015;3:1-5.

12. Sastroasmoro $S$, Ismael $S$, penyunting. Dasar-dasar metodologi penelitian klinis. Jakarta: Sagung Seto; 2008. 